\title{
The Molecular Diagnosis Protocols of New Coronavirus (COVID-19); Specificity and Sensitivity an Overview
}

\author{
Abdullah Ahmed Hama \\ Medical Laboratory Department \\ Technical College of Health \\ Research Center \\ Sulaimani Polytechnic University \\ Sulaimani, Iraq \\ abdullah.hama@spu.edu.iq \\ Fatima Mahmud Ali \\ Nursing Department \\ Sulaimani Technical Institute \\ Research Center \\ Sulaimani Polytechnic University \\ Sulaimani, Iraq \\ fatimah.ali@spu.edu.iq
Sardar Muhammad Wli
Nursing Department
Technical College of Health Research Center
Sulaimani Polytechnic University
Sulaimani, Iraq
sardar.weli@spu.edu.iq

Othman Abdulrahman Mohammed

Medical Laboratory Science

Technical College of Applied Science in Halabja Research Center

Sulaimani Polytechnic University

Sulaimani, Iraq

othman.mohammed@spu.edu.iq

\author{
Osama Hamid Shareef \\ Medical Laboratory Science \\ Technical College of Applied Science in Halabja \\ Research Center \\ Sulaimani Polytechnic University \\ Sulaimani, Iraq \\ osama.shareef@spu.edu.iq
}

Sabiha Sharif

Medical Laboratory Department

Technical College of Health

Research Center

Sulaimani Polytechnic University

Sulaimani, Iraq

sabiha_sh@yahoo.com

\author{
Syamand Ahmed Qadir \\ Medical Laboratory Science \\ Technical College of Applied Science in Halabja \\ Research center \\ Sulaimani Polytechnic University \\ Sulaimani, Kurdistan-Iraq \\ syamand.qadir@spu.edu.iq
}

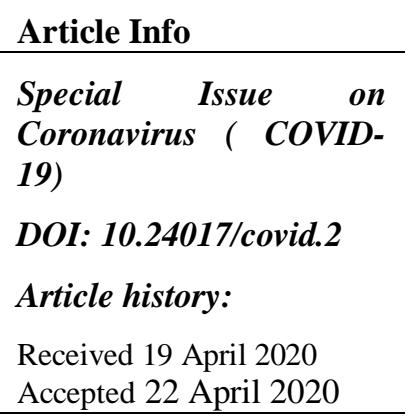

\begin{abstract}
Acute respiratory tract infection is a common public health concern worldwide a new emerging contagious virus (COVID2019) or SARSC- 2 causing a pandemic pneumonia outbreak, The main transmission route of this virus is through droplets from respiratory made during sneezing or coughing of infected people like the recent viral infection of severe acute respiratory syndrome (SARS-CoV1) and the Middle East respiratory syndrome (MERS). Many epidemiological factors have a crucial role in promoting the
\end{abstract}


Keywords:

COVID-19, new

coronavirus,

DNA marker,

respiratory viral infection. diagnostic methods,

transmission of the COVID-2019 that makes the disease as an emerging and global alarming against this new coronavirus. Early diagnosis of the etiological agents is critical for appropriate management, controlling plan, protection, and treatment. The new outbreak of COVID-19 can be detected by different molecular protocols. Quantitative polymerase chain reaction $(q P C R)$ is the recommended technique used with varied sensitivity due to primers variation and specimen type. The reliable, high specific and sensitive diagnosis protocols are necessary for an emerging control plan. This study will review and explore the most available methods of molecular identification and primers for the diagnosis of the new coronavirus (COVID-19). This review will also open the new clues to develop and select appropriate diagnosis panel and specific primers for new coronavirus. In conclusion of this review, the RNA dependent RNA polymerase (RdRp) and RdRp/Hel protocols will be valuable to distinguish the COVID-19 from the SARS-CoV and the other respiratory viral pathogens.

Copyright () 2020 Kurdistan Journal of Applied Research. All rights reserved.

\section{INTRODUCTION}

Seafood Wholesale Market in Wuhan, China, caused an alarming contagious primary atypical viral of pneumonia among people that broke out in December 2019. The outbreak then spread over China and other countries quickly. The new coronavirus (COVID-19) was firstly detected and confirmed by Chinese health authorities in January 2020. The virus was identified as an animal origin disease (zoonotic virus), similar to the MERS and SARS coronaviruses [1]. Coronaviruses are belonging to the family Coronaviridae, order Nidovirales and subgenus Sarbecovirus, The researchers described seven types of coronavirus (COVID19 ) is the new one of this cluster. [2]. The viral genome of the virus can encode four structural proteins, spike (S) protein is the one of the important protein which is restricted to a special receptor called angiotensin-converting enzyme 2 (ACE2) and arbitrates in viral attachments to the host cell and viral infection[3]. Recent epidemiological data indicate that the COVID-19 may a genetically modified virus of bat coronavirus. Nevertheless, this concept needs to be approved, and the potential reservoir or intermede host(s) are still unknown [4],[5].

Over the last two decades, the two beta-coronaviruses; SARS-CoV-1 [6,7,] and MERS-CoV, $[8,9]$ have infected more than 10000 cumulative cases with relatively high mortality rates of $10 \%$, and $37 \%$ respectively, while, fortunately, the most human cases of the coronavirus are mild. The novel virus (COVID-19) has been designated in February 2020, by the World Health Organization, and this virus is pointed out as SARS-CoV-2, initially was known as 2019n-CoV [10]. Due to the genetic identity of the SARS-CoV1, the virus was named as SARS-CoV2, while it has differences in the disease spectrum and route of transmission [11]. It is not known well how the virus can spread among people in a short period, but it is recognized that the virus can transmit in chains involving several links. The droplets of the respiratory produced during sneezing or coughing from an infected person are the main route of transmission similar to SARS and MERS [12]. The viral genome (RNA) was isolated from respiratory tract specimens of asymptomatic individuals [13, 14], and the transmission of the virus during the incubation period among asymptomatic individuals have also been described $[15,16]$. Also, the genetic matter (RNA) has been isolated from respiratory droplets, saliva, 
and other body fluids, such as blood and fecal specimens that may contain the infectious virus. It is still not proved that the virus can transmit through the placenta to the fetus during pregnancy or through breastfeeding, and there is also no enough information about the transmission of the coronavirus through, seminal and vaginal discharges during delivery $[17,18]$. The severity of the COVID-19 infection ranging from mild to severe pneumonia leading to dry cough and breath shorten. The WHO indicated the mild infections recover in around two weeks, while it takes three to six weeks for severe infections [6].

The molecular diagnostic protocols (qPCR) are the most specific and sensitive, the genome of the COVID-19 is a single strand RNA, so the RT-PCR is applied for identification of the virus in suspected patients [19]. Serological testing for the COVID-19 diagnosis is yet in development [20]. The number of COVID-19 is still increasing worldwide. Travelers from China had an essential role in virus spreading through the word. The epidemiological data indicate the morbidity and mortality rate of the new coronavirus has dramatically increased [21]. The most cases of the COVID-19 were recorded among age groups of 30 to 79 years old which is countered about $87 \%$ of cases, $1 \%$ of cases were from children younger than 9 years, aged, 10 to 19 years old were only counted $1 \%$, but higher percentage $(3 \%)$ were aged more than 79 years, the male to female ratio was approximately equal. The infection rate among males was $51 \%$, but $49 \%$ for females, and $4 \%$ of the human cases were recorded among health care workers. Compering to the adults, children were infected much less, and the cases reported among children were in family clusters or those children have frequent contact with a suspected person[22],[23].

\section{METHODS AND MATERIALS}

To Access The Diagnosis Techniques Of Covid-19 Around The World, And Compare The Results Of Each Protocol We Reached Systematically The Scientific Medical Software Such As Science Direct, Pubmed, The Web Of Science, Google Scholar And Scopus. The Review Included The Most Articles Reporting Diagnostic Methods Of 2019-Ncov, Including Physical Examination, Serology, Ct-Scan, Serology, Molecular Diagnosis, And Real-Time Pcr. The Systematic Search Was Achieved Using The Specific Key Terms: (Covid-19 Diagnosis, Molecular Diagnosis Of The Virus, Sars-Cov Diagnosis Method, Mers-Cov Diagnosis Techniques, And Specific Primer For Coronavirus Detection). The Most Related Published Articles With New Coronavirus Diagnosis From December 2019 To April 2020 Were Included.

\section{RESULTS}

\subsection{Clinical manifestation}

The infected cases of the COVID-19 have some important symptoms including, fatigue, fever, dyspnea, muscle ache, dry cough, and nasal congestion, or runny nose [4] [24]. Despite these common symptoms, the researchers claimed that fever by COVID-19 is one of the basic symptoms of viral infection [25].

\subsection{Physical observation}

The coronavirus disease has some phases regarding presenting the symptoms that include: Mild, Moderate, Severe, and Critical phases. The patients that have mild and moderate symptoms may not show clinical signs, whereas, patients with critical and severe situations may have respiratory symptoms such as restlessness, dyspnea (shortness of breath) [25].

\subsection{Imaging examination}

CT scan was strongly suggested by the researchers and physicians because of the imaging way findings the exact area of the infection in the chest and follows the patients while commended treatment course is taken. The imaging results will differ with the patient's immunity, scanning time, age, disease stage. The imaging appearance of lesions appears (dominant) distribution of 
lesions in the vascular bundles of the lungs, (quantity) for example number of lesions, (shape) nodular or grid-like, or (density) interlobular septal the bronchial wall thickening [25].

When the illness proceeded to develop, the subsegmental areas of consolidation and bilateral multiple lobular might appear on a chest CT scan. Importantly, the chest CT check showed up before the positive for the RT-PCR test in a few cases. Lungs of old infected persons are more likely diffuse and broad imaging than those of the more youthful persons [26], [27]. The lungs of mature patients appeared more diffuse and broad imaging than those of the more youthful patients. Also, Huang and colleagues explained that all patients (41 patients) had chest CT images they have abnormalities in the lung on admission. Later on, the CT images of their chest appeared bilateral ground-glass opacity, while the consolidation had been resolved [24]. Among 1014 patients, 888 (88\%) showed positive by CT scan, while 601 (59\%) of them detected by RT- PCR, this finding suggests that CT-scan may be used as a fast and more sensitive diagnosis technique of the COVID-19 [28].

\subsection{Some routine laboratory findings}

Some laboratory tests are also present for the identification of the COVID-19 infection includes C-reactive protein (CRP), kidney and liver function, myoglobin, myocardial enzyme, ESR, Procalcitonin (PCT), D-dimer, blood gas analysis, lactate, General Urine parameters, tuberculosis subgroups, inflammatory factors (IL-6, IL-10, TNF, coagulation image, anti-acid staining, complement [26]. At the beginning of the illness, WBC is decreased or stays at normal range, when both lymphocyte and/or CD8 T and CD4 cells are decreased. In these cases, it is generally recommended that further blood analysis after 3 days. [25].

\subsection{Serological test}

$\mathrm{N}$ protein of the SARSr-CoV Rp3 which has \%90 similarity with COVID-19 protein was developed as an antigen for SARSr-CoV for IgM and IgG (ELISA) assay [29]. The serological test yet in development to be highly specific and sensitive for COVID-19 detection. Serological diagnosis is essential for the epidemiological study and in cases where RNA isolation is difficult due to less amount of specimens or degradation of the virus genome.

\subsection{Molecular diagnosis and PCR}

The Chinese researchers were capable to identify a viral nucleic acid (RNA) from a patient within a time on Jan 2020 and they shared a sequence of the viral genome with National Institutes of Health (GenBank) database[30]. Upon genome sharing of the new coronavirus, the CDC developed a diagnosis protocol using RT-PCR analysis for the lower and upper respiratory specimens. The genome of the $2019-\mathrm{nCoV}$ was at least has $70 \%$ identity to the genetic of SARS-CoV [31].

The RT- PCR was successfully used to amplify the virus genome sinisterly and some genes were selected to be amplified specifically for this virus such as E- gene (Envelope gene) [32]. This diagnosis panel has been applied by about 35 clinical laboratories. The confirmatory RNA-dependent RNA polymerase-gene (RdRp) and N-gene of nucleoprotein were also used by 33 and 21 clinical laboratories, respectively [26].

\subsection{Real-Time Polymerase Chain Reaction}

Due to the close similarity of the SARS-CoV-1 and MERS virus, the RT-PCR technique was successfully used. A quantitative RT- PCR specific to the 1b section of the SARS-Cov which was used by Poon and his colleagues. The supplier of the diagnosis kit was Applied Biosystems and the two specific primer sequences [33].

Hung et al. used the commercial RT-PCR kits from Qiagen and Applied Biosystems for SARS-Cov1 detection in clinical samples.The primers were: forward 5'CAGAACGCTGTAGCTTCAAAAATCT-3' ${ }^{\prime}$ and reverse 5'TCAGAACCCTGTGATGAATCAACAG-3' [34]. The complex PCR technique has been used for identifying (MERS-CoV) by Poon and his colleagues [33], they screened the clinical 
samples using Roche Magna Pure LC kits, with amplification targeting the upstream E region (upE) and the ORF1a for confirmation. When both assays were positive, the results can be regarded as positive, when both assays (first and second) were differing from each other, or if the result of the RT-PCR was not clear, a new sample will be taken for more analysis as a confirmation test. Since the appearance of 2019-nCoV, the RT-PCR technique remains a valuable and sensitive diagnostic method. The sample types and period of sample collection have great effects on the diagnosis of 2019-nCoV [34].

The CDC diagnostic panel for COVID-19 is an RT-PCR technique for the suspected individual as a quantitative ideal method. The specific region of the virus nucleic acid (RNA) from the different clinical specimens of the respiratory tract including respiratory tract swab, sputum, noso-phyrengial, aspiration from the lower respiratory tract, nasal aspirate, nosophyrengial wash/aspirate and Nosal discharges is taken [35].

It was found that the respiratory specimens are better than serum samples for RT-PCR test, and a large amount of the virus can be detected at the beginning of the disease despite the mild symptoms [36]. In the United State, Holshue and his colleagues isolated the genome of the COVID-19 successfully from respiratory aspiration and stool specimens and the RT-PCR process was positive, while serum analysis was negative [30].

The specific RT-PCR protocols were published to confirm the COVID-19 cases, with different PCR kits suppliers, there are various primers for the COVID-19[29]. Specific primers (two sets) were used for COVID-19 diagnosis open reading frame 1a or $1 \mathrm{~b}$, the protein of the nucleocapsid this can be applied as a laboratory-confirmed test. Moreover, they concluded that a number of the cycle threshold value (Ct-value) is important to determine the case as a positive or negative [20]. In the United States of America, the initial case was recorded by Holshue and his colleagues developed rRT-PCR protocol from the sequences of the viral genome, Clinical samples were verified, similar to earlier analytical assess for the other severe respiratory diseases such as SARS-CoV and MERS-CoV, the $\mathrm{N}$ gene was targeted, this The most common COVID-19 primers were presented in Table (1).

France's first case was recorded by Bernard Stoecklin and his teammate [37], the Test has relied on the RT-PCR procedure supplied by Charite [32] as well as the use of RT-PCR particularly the RdRp (four targets) designed at Institute Pasteur (RdRp-IP) with a hghi specificity. The QIAGEN, Hilden, Germany, and Invitrogen, Darmstadt, Germany designed a set of primers for RdRp gene, the oligonucleotides were produced by Tib-Molbiol (Berlin, Germany) [32]. Recently Chan and his colleagues have developed a new RdRp/Hel protocol, this protocol is more specific and sensitive than the other previous diagnosis tools [38]. In another study, the RT-PCR was successfully used for identifying the new coronavirus cases by purchasing the kits from different sources (Qiagen, Hilden, Germany, Applied Biosystems, USA, PowerCheck ${ }^{\mathrm{TM}}$ SARS-CoV-2 and KogeneBiotech, Seoul, Korea) [39].

Furthermore, Chu and his team have developed 1-step quantitative real-time reversetranscription RT-PCR assays to allow the recognition of patients quickly and to identify both specific parts of ORF1 and $\mathrm{N}$ of the viral RNA [40]. The sets consist of primer and probe. which were produced to identify the COVID-19 and other viruses (SARS), two respiratory samples were also tested by this technique from two positive cases of the COVID-19, these protocols allow to use of genetic materials of SARS-CoV1 as positive controls [41].

Table 1: The recent diagnosis protocols for the COVID-19.

\begin{tabular}{|c|c|c|c|c|}
\hline Assay & Primer name & Primer sequence & Primer size & $\begin{array}{l}\text { Refer } \\
\text { ences }\end{array}$ \\
\hline \multirow{2}{*}{ E gene } & (E_Sarbeco_F) & $5^{\prime}$ - ACAGGTACGTTAATAGTTAATAGCGT -3' & 26 & \multirow[t]{2}{*}{ [32] } \\
\hline & (E_Sarbeco_R) & 5'- ATATTGCAGCAGTACGCACACA -3' & 22 & \\
\hline \multirow{2}{*}{ RdRP gene } & (RdRp_SARSr-F) & 5'-GTGARATGGTCATGTGTGGCGG -3' & 22 & \multirow[t]{2}{*}{ [32] } \\
\hline & (RdRp_SARSr-R) & 5'-CARATGTTAAASACACTATTAGCATA-3' & 26 & \\
\hline $\mathrm{N}$ gene & (N_Sarbeco_F) & $5^{\prime}$ - CACATTGGCACCCGCAATC-3' & 19 & [32] \\
\hline
\end{tabular}




\begin{tabular}{|c|c|c|c|c|}
\hline & (N_Sarbeco_R) & 5'- GAGGAACGAGAAGAGGCTTG -3' & 20 & \\
\hline \multirow{2}{*}{ S gene } & (RBD-qF1) & 5'- CAATGGTTTAACAGGCACAGG -3' & 21 & \multirow[t]{2}{*}[29]{} \\
\hline & (RBD-qR1) & 5'- CTCAAGTGTCTGTGGATCACG -3' & 21 & \\
\hline \multirow{3}{*}{$\mathrm{N}$ gene } & forward primer & 5'-CTC AGT CCA AGA TGG TAT TTC T-3' & 22 & \multirow{3}{*}[41]{} \\
\hline & reverse primer & 5'-AGC ACC ATA GGG AAG TCC-3' & 18 & \\
\hline & probe & $\begin{array}{l}\text { 5'-FAM-ACC TAG GAA CTG GCC CAG AAG CT- } \\
\text { BHQ1-3' }\end{array}$ & 23 & \\
\hline \multirow{3}{*}{ ORF1ab } & forward primer & 5'-TCA TTG TTA ATG CCT ATA TTA ACC-3' & 24 & \multirow{3}{*}[41]{} \\
\hline & reverse primer & 5'-CAC TTA ATG TAA GGC TTT GTT AAG-3' & 24 & \\
\hline & probe & $\begin{array}{l}\text { 5'-FAM- AAC TGC AGA GTC ACA TGT TGA CA- } \\
\text { BHQ1-3' }\end{array}$ & 23 & \\
\hline \multirow{2}{*}{ Orf1ab } & $\begin{array}{l}\text { (Orf1ab-RPA- } \\
\text { Forward_v1) }\end{array}$ & $\begin{array}{c}5^{\prime}- \\
\text { GAAATTAATACGACTCACTATAGGGCGAAGTTGT } \\
\text { AGGAGACATTAT ACTTAAACC-3' }\end{array}$ & 55 & \multirow[t]{2}{*}[42]{} \\
\hline & $\begin{array}{l}\text { (Orf1ab-RPA- } \\
\text { Reverse_v1) }\end{array}$ & 5'-TAGTAAGACTAGAATTGTCTACATAAGCAGC-3' & 30 & \\
\hline \multirow[t]{2}{*}{ S gene } & $\begin{array}{l}(\text { S-RPA- } \\
\text { Forward_v1) }\end{array}$ & $\begin{array}{c}5^{\prime}- \\
\text { GAAATTAATACGACTCACTATAGGGAGGTTTCAA } \\
\text { ACTTTACTTGCTT TACATAGA-3' }\end{array}$ & 55 & \multirow[t]{2}{*}[42]{} \\
\hline & $\begin{array}{c}\text { (S-RPA- } \\
\text { Reverse_v1) }\end{array}$ & 5'-TCCTAGGTTGAAGATAACCCACATAATAAG-3' & 30 & \\
\hline \multirow{3}{*}{ ORF1 ab } & forward primer & 5'-AGAAGATTGGTTAGATGATGATAGT-3' & 25 & \multirow{3}{*}[43]{} \\
\hline & reverse primer & 5'-TTCCATCTCTAATTGAGGTTGAACC-3' & 25 & \\
\hline & probe & $\begin{array}{c}\text { 5'-FAM-TCCTCACTGCCGTCTTGTTGACCA- BHQ1 - } \\
3 \text {, }\end{array}$ & 24 & \\
\hline \multirow{3}{*}{$\begin{array}{l}\text { Covid-19 } \\
\text { RdRp/Hel }\end{array}$} & RdRp/Hel Forward & 5'-CGCATACAGTCTTRCAGGCT-3' & & \multirow{3}{*}[38]{} \\
\hline & RdRp/Hel Reverse & 5'-GTGTGATGTTGAWATGACATGGTC-3' & & \\
\hline & Probe & $\begin{array}{c}\text { FAM - TTAAGATGTGGTGCTTGCATACGTAGAC - } \\
\text { 1ABkFQ }\end{array}$ & 28 & \\
\hline \multirow{3}{*}{$\begin{array}{l}\text { COVID }-19- \\
\text { S }\end{array}$} & Spike/ Forward & 5'-CCTACTAAATTAAATGATCTCTGCTTTACT-3' & 30 & \multirow{3}{*}[38]{} \\
\hline & Spike/ Reverse & 5'-CAAGCTATAACGCAGCCTGTA-3' & 21 & \\
\hline & Probe & HEX -CGCTCCAGGGCAAACTGGAAAG -IABkFQ & 22 & \\
\hline \multirow{3}{*}{$\begin{array}{l}\text { COVID }-19- \\
\quad \mathrm{N}\end{array}$} & $\begin{array}{l}\text { Nucleocapsid/ } \\
\text { Forward }\end{array}$ & GCGTTCTTCGGAATGTCG & 18 & \multirow{3}{*}[38]{} \\
\hline & $\begin{array}{l}\text { Nucleocapsid/ } \\
\text { reverse }\end{array}$ & TTGGATCTTTGTCATCCAATTTG & 23 & \\
\hline & Probe & FAM -AACGTGGTTGACCTACACAGST -1ABkFQ & 22 & \\
\hline
\end{tabular}

\section{DISCUSSION}

Identification of the infectious viral pathogens is crucial to find and make a proper strategical control plan, the right treatment, and breaking the outbreak cycle. Quick diagnostics of infectious agents have essential functions in early controlling of the outbreaks in all countries. Due to the rapid transmission of viral infection, especially respiratory infection, viruses, and airborne viruses, proper and accurate diagnosis techniques are the valuable steps to prevent the transmission and overcome of infectious diseases [32]. There are many laboratory methods for the diagnosis of the viruses, including identifying specific antibodies, identifying genetic information of the virus, serological technique, and culturing the virus. Culturing the virus is a time and labor-consuming technique as compared to other techniques. However, this assay is more beneficial in the first stage of an epidemic and pandemic cases before the other detection assays. Viral cultures are also able to apply in both trials of antiviral and vaccine 
evaluations[44],[45].

Current laboratory techniques for the identification and amplification of genetic material of both of SARS-CoV and MERS-CoV are RT-PCR, reverse transcription PCR and, reverse transcription loop-mediated isothermal amplification (RT-LAMP) [33]; The amplification of nucleic acid is usually the standards for the diagnosis cases of MERS-CoV because this method has the highest sensitivity at the onset of the acute phase of the disease [46]. Regarding the current infectious pandemic COVID-19 virus, Chinese health authorities have released the RNA sequence of the virus in portals of GenBank and GISAID (https://www. gisaid.org) to help the scientists for the identification of the new cases COVID-19 and finding a suitable treatment [32]. Also, there are some of the important assays which are used to identify the new coronavirus in Wuhan of China, as enforced by the guidance of WHO on the suspected cases including nucleic acid amplification tests (NAAT), serological testing, Viral genome amplification and sequencing [47].

In Germany, there was initially designed a diagnostic assay for the COVID-19, in the normal workflow, it was suggested to use E gene test, this test can act as the first stage of the screening tool and following by the RdRP gene protocol which acts as confirmatory testing. In this application, two-color technologies can be used to distinguish COVID-19 from SARSCoV RNA (both probes positive), when the second one is used as a positive control. Instead of this option, clinical centers can run the RdRp assay with a specific probe for the COVID-19 only. All assays were much sensitive and the reasonable result was gained for both RdRp and E gene. These tests were also not interfering with other types of coronavirus [32].

In a comparison study, Chan et at [38] compared three new RT-PCR protocols targeting RdRp/helicase (Hel), spike (S), and nucleocapsid (N) genes of COVID-19 with RdRp-P2 assay which is adapted in European laboratories (>30). They reported that theRdRp/Hel assay had a high level of sensitivity and specificity and the lowest limit of identification of the viral genome.

Hong Kong University has also designed a protocol to define COVID-19 in human clinical sources. This assay was reactive with coronaviruses which belong to subgenus Sarbecovirus(SARS-CoV, SARS, and COVID-19).The genetic material of the COVID-19 in humans and animals is more diverse and it is not fully determined. Therefore, in this suggested protocol, SARS-CoV is used as a positive control. It is also suggested to use the $\mathrm{N}$ gene RT-PCR and ORF $b$ test as confirmatory tests. In positive PCR results, analyses of the viral sequence will further help to enforce the positive result and to distinguish the positive control SARS-CoV from COVID-19. Although this approach is more sensitive, it has only been used when a positive control SARS-CoV RNA is present [48].

The US Centers for Control Disease and Prevention follows an assay on the RT-PCR for the identification of the COVID-19 using special primers and probes which were initially designed for SARS-like coronavirus and then for the identification of the COVID-19. However, this protocol has some limitations, users who work with this protocol should have sufficient experience and knowledge about the protocol and analyzing data. False-negative results may occur because of using not enough genetic material of the virus in the sample. The false-negative result may also appear due to improper specimen collection or the peak of the COVID-19 during infection has not been determined. Also, genetic variability might be happening in RNA viruses, this behavior can result in a mismatch of sequences between the viral genetic information with primer and probes results in a decrease in the performance of the test and obtaining false-negative results [35]. As suggested, the initial sample volume in RNA extraction needs to be increased for the identification of SARS-CoV. This point might also be considered during establishing the assay with the COVID-19 [33].

Apart from the detection of the genetic material of viruses, the serological assay can also be used with lower the sensitivity of antibody detection assay than the molecular techniques. Serological assay such as ELISA and IIFT assays which are successful in the diagnosis of infections. However, the lag period of the antibodies specifically targeting the virus might belong which usually appears from 14 to 28 days after the appearance of the illness [46],[49],[50]. Moreover, as it is found in MERS-COV cases, a low level of antibody 
production after two weeks might be related to the mortality rate of this infection. For this reason, it is suggested that follow serological diagnoses assay when nucleic acid amplification are not present [51],[49]

X-rays or thorax CT imaging can also use for imaging patients, unilateral or bilateral involvement, compatible with viral pneumonia [24]. A correlation between chest CT scan and RT-PCR assays in the COVID-19 is made. This has shown that the chest CT scan has a high level of sensitivity for the identification of the COVID-19. Ai, and his colleagues (2019) indicated the chest CT scan might be used as one of the alternative primary devices for the current COVID-19detection [28]. Some other studies have suggested using CT-scan as an alternative diagnostic method for the COVID-19. [52], [28].

\section{Conclusion}

The results of this systematic review concluded the following points

- The RdRp/Hel is a new and reliable protocol for the COVID-19 diagnosis with high sensitivity and specificity.

- $\quad$ The RNA dependent RNA polymerase (RdRP) and RdRp/Hel protocols can be used to distinguish the COVID-19 from the SARS-CoV and the other respiratory viral pathogens.

- Positive results of the RT-PCR are meet active infection with the COVID-19 but it cannot rule out co-infection with other viruses and bacterial infection. The detected agents from suspected patients may not be the definitive cause of disease.

- The respiratory specimens and stool samples for viral genome isolation are more efficient than the serum which can be used in severe cases.

- The sampling technique, specimen type and period of sample collection have a real impact on the quantity of viral genomic information and it reflects negatively on the diagnosis protocol.

- The chest CT scan will be helpful for COVID-19 diagnosis in the case of insufficient nucleic acid for RT-PCR and in emergency cases.

\section{ACKNOWLEDGMENT}

The authors would like to thank the presidency of Sulaimani Polytechnic University and Research center of SPU for there cooperation and encouragement.

\section{REFERENCE}

[1] M.Shen, Z. Peng, Y. Xiao, L. Zhang, "Modelling the epidemic trend of the 2019 novel coronavirus outbreak in China", bioRxiv.,.916726. 2020. https://doi.org/10.1101/2020.01.23.916726

[2] D.D. Richman, R.J. Whitley, F.G. Hayden, "Clinical virology", 4th edn. Washington, DC: ASM Press,2016.

[3] Z.Y. Zu, D.J. Meng, P.X. Peng, C.Wen , Q.N.Qian , M.L.Guang , J.Z. Long, " Coronavirus Disease 2019 (COVID-19): A Perspective from China", Radiology, vol. 2019, p. 200490, 2020. https://doi.org/10.1148/radiol.2020200490

[4] N.Zhu, D. Zhang, W.Wang, L. Xingwang, Y. Bo, S. Jingdong, Zh. Xiang, H. Baoying, S. Weifeng, L. Roujian, N. Peihua, Zh. Faxian, et al, " A novel coronavirus from patients with pneumonia in China, 2019 ", N. Engl. J. Med., vol.382,pp.727-733, 2020. DOI: 10.1056/NEJMoa2001017.

[5] R.Lu, X. Zhao,J. Li,N. Peihua, Y.Bo, W. Honglong, et al. "Genomic characterisation and epidemiology of 2019 novel coronavirus: implications for virus origins and receptor binding", Lanc,J, vol.395,pp. 565-574, 2020. DOI: 10.1016/S0140-6736(20)30251-8.

[6] T.G. Ksiazek ,D. Erdman ,C.S. Goldsmith,S.R. Zaki, T.Peret, S.Emery, S.Tong ,C. Urbani, J.A. Comer , W Lim , P.E. Rollin, S.F. Dowell , A.E. Ling, C.D. ,W.J. , et al. "A novel coronavirus associated with severe acute respiratory syndrome" N. Eng.1 J. Med.,vol.348, pp.1953-1966, 2003.

[7] T.G. Kuiken, R.A.M. Fouchier, M. Schutten, R.F. Guus, R.Debby, et al, "Newly discovered coronavirus as the primary cause of severe acute respiratory syndrome", Lanc, J,vol. 362, pp.263-270, 2003. DOI: 10.1016/S0140-6736(03)13967-0.

[8] R.J. de Groot,S.C. Baker, R.S. Baric, S.B. Caroline,D. Christian, E.Luis, et al, "Middle East respiratory syndrome coronavirus (MERS-CoV): announcement of the Coronavirus Study Group", J. Virol, vol.87, pp,7790-7792, 2013. DOI: 10.1128/JVI.01244-13.

[9] A.M. Zaki , S. van Boheemen, T.M.Bestebroer , A.D.M.E. Osterhaus, R.A.M. Fouchier, " Isolation of a novel coronavirus from a man with pneumonia in Saudi Arabia", N. Engl. J. Med,vol.367, pp.1814-1820, 2012. 
[10] World Health Organization, "Summary of Probable SARS Cases with Onset of Illness from 1 November 2002 to January 2003.3003. http://www.who.int/csr/sars/country/table2004_04_21/en/index.html

[11] World Health Organization, "Middle East respiratory syndrome coronavirus (MERS-CoV)" Repoet of WHO.2020 http://www.who.int/emergencies/mers-cov/en/

[12] World Health Organization, " Director -Generals remarks at the media briefing on 2019-nCov". 2020. https://www.who.int/dg/speeches/detail/who-director-general-s-remarks-at-the-media-briefing-on-2019-ncovon-11-february-2020

[13] A.E.Gorbalenya, C. B. Susan, S.B. Ralph,J. de.G. Raoul, D. Christian, A. G. Anastasia, et al., " Severe acute respiratory syndrome-related coronavirus: the species and its viruses - a statement of the Coronavirus Study Group", bioRxiv preprint, 2020. DOI: 10.1101/2020.02.07.

[14] J.F.Chan, S.Yuan, K.H. Kok, K.T.Kelvin, C. Hin, Y.Jin et al, "A familial cluster of pneumonia associated with the 2019 novel coronavirus indicating person-to-person transmission: a study of a family cluster", Lanc.J, vol.395,pp.514-523, 2020. DOI: 10.1016/S0140-6736(20)30154-9.

[15] S.Hoehl, A. Berger, M.Kortenbusch, et al, " Evidence of SARS-CoV-2 Infection in Returning Travelers from Wuhan, China", N. Engl. J. Med., vol. 382, pp.1278-1280 2020. DOI: 10.1056/NEJMc2001899.

[16] L. Zou , F. Ruan, M. Huang, L.Liang, H. Huang, Z. Hong, et al, " SARS-CoV-2 Viral. Load in Upper Respiratory Specimens of Infected Patients", N. Engl. J.Med., vol. 382, pp.1177-1179, 2020 DOI: 10.1056/NEJMc2001737.

[17] H. Chen, J. Guo, C. Wang,L. Fan, Y.Xuechen, et al, " Clinical characteristics and intrauterine vertical transmission potential of COVID-19 infection in nine pregnant women: a retrospective review of medical records", Lanc.J.,vol.395,pp.809-815, 2020. DOI:10.1016/S0140-6736(20)30360-3.

[18] H. Zhu, L.Wang, C.Fang,P.Sicong, Zh.Lianhong, Ch. Guiping, X.Shiwen, Zh. Wenhao, " Clinical analysis of 10 neonates born to mothers with 2019-nCoV pneumonia", Transl. Pediatr., vol. 9,pp. 51-60, 2020. DOI: $10.21037 /$ tp.2020.02.06.

[19] World Health Organization, "Laboratory testing for 2019 novel coronavirus (2019-nCoV) in suspected human cases", 17 January 2020. https://apps.who.int/iris/handle/10665/330676.

[20] Z. Li, Y. Yi, X. Luo, N.Xiong, Y.Liu, S.Li, R.Sun,Y. Wang, B.Hu, et al, " Development and clinical application of a rapid IgM-IgG combined antibody test for SARS-CoV-2 infection diagnosis", J. Med. Virol., 2020 Feb 27. DOI: $10.1002 /$ imv. 25727.

[21] World Health Organization, "Coronavirus disease (COVID-2019) situation reports", 2020.

[22] Z. M. Chen, J.F. Fu, Q.Shu,Y.H. Chen, C.Z. Hua, F.B. Li, R. Lin, L.F. Tang, et al, " Diagnosis and treatment recommendations for pediatric respiratory infection caused by the 2019 novel coronavirus", World. J. Pediatr. 2020. DOi: 10.1007/s12519-020-00345-5.

[23] K.L. Shen, Y.H.Yang, " Diagnosis and treatment of 2019 novel coronavirus infection in children: a pressing issue", World. J. Pediatr. 2020. DOI: 10.1007/s12519-020-00344-6

[24] C.Huang, Y. Wang, X. Li, L. Ren, J. Zhao, Y. Hu, L. Zhang, G. Fan, J. Xu, X. Gu et al. "Clinical features of patients infected with 2019 novel" Lanc. J., vol.395pp.497-506, 2020. DOI: 10.1016/S0140-6736(20)30183-5.

[25] J. Ying-Hui, C.Lin,Ch. Zhen-Shun, Ch.Hong, D.Tong,F. Yi-Pin,F. Cheng, H. et al., "A rapid advice guideline for the diagnosis and treatment of 2019 novel coronavirus (2019-nCoV) infected pneumonia (standard version) ", M. Med.Rech.,vol. 7, No. 4-4.2020. DOI: 10.1186/s40779-020-0233-6.

[26] J. She, J. Jiang, L. Ye, L. Hu, C. Bai, and Y. Song, "2019 novel coronavirus of pneumonia in Wuhan, China: emerging attack and management strategies", Clin. Trans.l Med.,( 9) 19, 2020. DOI: 10.1186/s40169-020$\underline{00271-\mathrm{z} .}$

[27] L.Xiaoqi,G. Zhenyu, X. Zuke,X. Jingliang,F. Bing, and L. Jiaqi, Liu, " Novel Coronavirus Pneumonia Outbreak in 2019: Computed Tomographic Findings in Two Cases", Korean journal of radiology, (21) ,pp. 365-68, 2020. DOI: 10.3348/kjr.2020.0078.

[28] T. Ai, Z. Yang, H. Hou,C. Zhan,C. Chen, W. Lv, Q. Tao, Z. Sun and L. Xia, "Correlation of Chest CT and RTPCR Testing in Coronavirus Disease 2019 (COVID-19) in China: A Report of 1014 Cases", Radiology, (80), 2, pp. 1-8, 2020. DOI : 10.1148/radiol.2020200642.

[29] P. Zhou, X. L. Yang, X. G. Wang, B. Hu, L. Zhang, W. Zhang, et al, "A pneumonia outbreak associated with a new coronavirus of probable bat origin",2020, Nature, vol. 579, No.7798, pp. 270-273, 2020. DOI: 10.1038/s41586-020-2012-7.

[30 ] M. L. Holshue, C. DeBolt, S. Lindquist, K. H. Lofy, J. Wiesman, H. Bruce, C. Spitters, et al., "First Case of 2019 Novel Coronavirus in the United States", N. Engl. J. Med.,vol. 382, pp. 929-936, 2020. DOI : 10.1056/NEJMoa2001191.

[31] D.S. Hui, I.E. Azhar, T. A. Madani, F. Ntoumi, R. Kock, O. Dar, G. Ippolito, T. D. McHugh, Z. A. Memish, C. Drosten, A. Zumla, and E. Petersen," The continuing 2019-nCoV epidemic threat of novel coronaviruses to global health - The latest 2019 novel coronavirus outbreak in Wuhan, China", Int.J. Infect. Dis., vol. 91,pp. 26466,2020

[32] V.M. Corman, O. Landt, M. Kaiser, R. Molenkamp, A. Meijer, D. K. W. Chu, T. Bleicker, etal., " Detection of 2019 novel coronavirus (2019-nCoV) by real-time RT-PCR", Euro. Surveill., vol.25, No.3, 2020. DOI: 10.2807/1560-7917.ES.2020.25.3.2000045.

[33] L.L. Poon, K. H. Chan, O. K. Wong, W. C. Yam, K. Y. Yuen, Y. Guan, Y. M. Lo, and J. S. Peiris, " Early diagnosis of SARS coronavirus infection by real time RT-PCR", J. Clin. Virol.,vol. 28, pp. 233-8. 2003.

[34 ] I. F. N. Hung, V. C. C. Cheng, A. K. L. Wu, B. S. F. Tang, K. H. Chan, C. M. Chu, M. M. L. et al., " Viral loads in clinical specimens and SARS manifestations", Emerging infectious diseases, vol. 10, pp. 1550-1557, 2004. 
[35] CDC, " CDC 2019-Novel Coronavirus (2019-nCoV) Real-Time RT-PCR Diagnostic Panel ", Centers for Diseade Control and Prevention. Division of Viral Diseases. 2020 https://www.fda.gov/media/134922/download

[36] J. Pang, M. X. Wang, I. Y. H. Ang, S. H. X. Tan, R. F. Lewis, J. I. Chen, R. A., et al. " Potential Rapid Diagnostics, Vaccine and Therapeutics for 2019 Novel Coronavirus (2019-nCoV): A Systematic Review", J. Clin. Med.,vol. 9. 2020. DOI: 10.3390/jcm9030623.

[37] B. S. Sibylle, R. Patrick, S. Yassoungo, M. Alexandra, C. Christine,S. Anne, M.Matthieu, M. Laure, N. Mathieu, B. Clément, Y.Estelle, B.Sylvie, I. Sophie, N. Duc, M. Denis, X. François, C. Scarlett Georges, Clément Lazarus, Anouk Tabaï, Morgane Stempfelet, Vincent Enouf, Bruno, L.B. Daniel, and Team Investigation, " First cases of coronavirus disease 2019 (COVID-19) in France: surveillance, investigations and control measures, January 2020", Euro. Surveill., vol. 25, 2020.

[38 ] J.F. Chan, C.C. Yip, K.K. To, T.H. Tang, S.C. Wong, K.H. Leung, A.Y. Fung, A.C. Ng, et al, "Improved molecular diagnosis of COVID-19 by the novel, highly sensitive and specific COVID-19-RdRp/Hel real-time reverse transcription-polymerase chain reaction assay validated in vitro and with clinical specimens", [published online ahead of print, 2020 Mar 4]. J. Clin. Microbiol,. JCM. 00310-20, 2020 DOI:10.1128/JCM.00310-20

[39] L. Jaegyun, J. Seunghyun, Y.S. Hyun, J.K. Moon, M.S. Yu, L. J. Wang, W. C. Kang, M. k. Yu, L. Baeckseung, and J.P. Sang, " Case of the Index Patient Who Caused Tertiary Transmission of COVID-19 Infection in Korea: the Application of Lopinavir/Ritonavir for the Treatment of COVID-19 Infected Pneumonia Monitored by Quantitative RT-PCR"', J. K. M.S., vol. 35, pp. e79-e79, 2020. DOI: 10.3346/jkms.2020.35.e79.

[40] D. K. W.Chu, Y. Pan, S. M. S. Cheng, K. P. Y. Hui, P. Krishnan, Y. Liu, D. Y. M. Ng, C. K. C. Wan, P. Yang, Q. Wang, M. Peiris, and L. L. M. Poon, " Molecular Diagnosis of a Novel Coronavirus (2019-nCoV) Causing an Outbreak of Pneumonia", Clin. Chem., vol 1;66 , No.4, pp.549-555, 2020. DOI: 10.1093/clinchem/hvaa029.

[41] K.Kai-qian F.Y. Chee,C. Lin, T.P.L. Raymond, M.M. Tze, M. Matthias, L.Jiahui, Y.C. Chia, N. Nadua, et al., "A Well Infant With Coronavirus Disease 2019 With High Viral Load ", Clin. Infect. Dis., no. February, pp. 2019-2021, 2020. DOI: 10.1093/cid/ciaa201

[42] N. Zhang, L. Wang, X. Deng, R. Liang, M. Su,C. He, L. Hu, Y. Su, J. Ren, F. Yu, L. Du, and S. Jiang, " Recent advances in the detection of respiratory virus infection in humans", j. M. V. , vol.92, No. 4, pp. 408417, 2020. DOI: $10.1002 / \mathrm{jmv} .25674$.

[43] Z. Hu, C. Song, C. Xu, G. Jin, Y. Chen, X, Xu, H. Ma, W. Chen, Y. Lin, Y.Zheng, J. Wang, Z. Hu, Y. Yi, H. Shen, " Clinical characteristics of 24 asymptomatic infections with COVID-19 screened among close contacts in Nanjing, China", Sci. China Life Sci., 2020. DOI: 10.1007/s11427-020-1661-4.

[44] J. F. W. Chan, S. Sridha, C.C. Yip, S. K. Lau,and P.C. Woo, " The role of laboratory diagnostics in emerging viral infections: the example of the Middle East respiratory syndrome epidemic", J. Microbio., vol. 55, No.3, pp. 172-182, 2017. DOI: 10.1007/s12275-017-7026-y.

[45] Y. Yin and R. G. Wunderink, " MERS, SARS and other coronaviruses as causes of pneumonia", Respirology, 23(2), 130-137, 2018. doi: 10.1111/resp.13196.

[46] C. Kelly-Cirino,L.T. Mazzola, A. Chua,C. J. Oxenford,and M.D. Van Kerkhove, "An updated roadmap for MERS-CoV research and product development: focus on diagnostics", BMJ Global Health, vol. 4(Suppl 2), e001105.2019. DOI: 10.1136/bmigh-2018-001105. eCollection 2019.

[47] World Health Organization (WHO), " Novel Coronavirus. (2019-nCoV) technical guidance: laboratory guidance. Geneva: WHO", [Accessed 08 March 2020]. Available from: https://www.who.int/emergencies/diseases/novel-coronavirus-2019/technical-guidance/laboratory-guidance

[48] HKU, " Detection of 2019 novel coronavirus (2019-nCoV) in suspected human cases by RT-PCR", LKS Faculty of Medicine School of Public Health, 2020. https://www.who.int/docs/defaultsource/coronaviruse/peiris-protocol-16-1-20.pdf?sfvrsn=af1aac73 4

[49] S. Al Johani, and A.H. Hajeer, " MERS-CoV diagnosis: An update", J. Infec. and Public Heal.,vol. 9, No.3,pp. 216 -219, 2016. DOI: 10.1016/j.jiph.2016.04.005

[50] J.H. Ko, M.A.Müller,H. Seok,G.E. Park, J.Y.Lee, S.Y.Cho,Y.E., et al. " Serologic responses of 42 MERScoronavirus-infected patients according to the disease severity", . Diagn. Microbiol. and Infecti. Dis.,vol 89, No.2, pp.106-111, 2017. doi: 10.1016/j.diagmicrobio.2017.07.006.

[51] World Health Organization(WHO), " Laboratory Testing for Middle East Respiratory Syndrome Coronavirus", Who, September 2013, 1-9, 2014. DOI: 0.1016/j.1wt.2018.09.079

[52] H.X. Bai, B. Hsieh, Z. Xiog, K. Halsey, J.W. Choi, T.M.L.Tran, et al. "Performance of radiologists in differentiating COVID-19 from viral pneumonia on chest CT," Radiology, p. 200823, 2020. DOI: $\underline{10.1148 / \text { radiol.2020200823. }}$ 